\title{
PREVALENCE OF GASTROINTESTINAL PARASITES IN CAMEL IN POTENTIAL AREAS OF ETHIOPIA (THE CASE OF AFAR REGIONAL STATE)
}

\author{
Endris F. AHMED ${ }^{1 \otimes} \otimes$, Weldegebrial G. AREGAWI ${ }^{2}$, Beksisa URGE 3 and Medina ENDRIS ${ }^{4}$ \\ ${ }_{1}^{1}$ Afar Pastoral and Agro-pastoral Research Institute, P.O. Box 16, Samara, Afar, Ethiopia \\ ${ }^{2}$ Ethiopian Institute of Agricultural Research, Mehoni Agricultural Research Center, P.O. Box , 47, Mekhoni, Tigray, Ethiopia \\ ${ }^{3}$ Ethiopian Institute of Agricultural Research, Holeta Agricultural Research Center, P.O. Box 2003, Addis Ababa, Ethiopia \\ ${ }^{4}$ Semera Regional Veterinary laboratory, Afar, Semera, P.O. Box 33, Semera, Afar, Ethiopia \\ Email: endrisf@yahoo.com \\ Supporting Information
}

\begin{abstract}
A cross sectional study was conducted from April, 2017 to October, 2018 to determine the prevalence of gastrointestinal tract (GIT) helminthes and protozoan parasites in relation to contributing risk factors in camels of afar region. Accordingly, a total of 407 camels were examined. Random and purposive sampling was made in the respective districts for screening of camels. Fecal samples were collected and processed by sedimentation and floatation methods. The coprological finding indicated that about $30.22 \%(n=$ 123) of the camels harbored and excreted helminthes and protozoan parasites. Of which, the prevalence of nematodes, protozoa, cestodes, and trematodes were 144 (35.38\%), 28 (22.76\%), 8 (6.50\%) and 5 (4.07\%), respectively. The most frequently encountered parasites were Strongylus sp. 68 (55.28\%), Trichuris sp. 40 (32.52\%) Strongyloides sp. 36 (29.27\%), Coccidia 28 (22.76\%), Moniezia 8 (6.50\%), and Paraphystomum 5 (4.07\%), respectively. $17.44 \%$ of the cases were single infection while $10.57 \%$ were mixed infections. Age and body condition of the animals were significantly associated $(P<0.05)$ with the occurrence of parasites. In conclusion, gastrointestinal parasites are the major health problems of camel in the study areas. Therefore, it is important to undertake the detailed epidemiological investigations such as seasonal dynamics, fecal culture for larvae recovery and species identification to generate parasite mitigation methods.
\end{abstract}

Keywords: Afar region, Camel, Gastrointestinal parasite, Prevalence, Risk factors.

\section{INTRODUCTION}

Camel is anatomically and physiologically well adapted to harsh climatic conditions of desert. They are valued as riding, baggage, drought animal as well as best food provider in the arid areas. Camels are important milk producers in arid lands and camel milk is an essential food for livelihood of people and it may be the only milk available in places where other milking animals cannot be maintained (Hoter et al., 2019). Camel is an important animal component of the fragile desert eco-system, with its unique bio-physiological characteristics, thus, has become an icon of adaptation to challenging ways of living in arid and semi-arid regions (Bikaner, 2008; Burger et al., 2019).

The production, productivity and health of camel are affected by several factors. Parasites and parasite borne diseases are the major constraints in improvement production and productivity efficiency (Djerbouh et al., 2018; Desta, 2019). Among important camel health problems, different types of gastrointestinal (GIT) parasites over emphasize camel production in the study areas (Barji et al., 2010).

Notwithstanding the immense action made to control GIT Parasitosis, farmers in Ethiopia continue to incur significant losses due to insufficient availability of information and best practices on the epidemiology of the GIT parasites (Fentahun, 2020). GIT parasites are associated stunted growth rate, weight loss, copious diarrhea, reduced feed intake, and anemia in severe cases which results in loss of production and productivity of domestic animals (Fentahun, 2020). In young stock, GIT parasitism is responsible to reduce growth rate by $30 \%$, even with a minimum level of parasite burden (Urge, 2020).

Despite these facts, information about the occurrence and species composition of GIT parasites of camel is limited in Afar region of Northern Ethiopia. This study were therefore conducted to generate recent information on the occurrence 
and species diversity of camel GIT parasites, identify risk factors associated with the occurrence of GIT parasites, and to recommend an appropriate helminthes control and prevention options that could be used in the camel rearing areas.

\section{MATERIALS AND METHODS}

\section{Study area}

The study was conducted from April to October 2018 in selected districts of Afar region. Afar National Regional State is one of the nine federal states of Ethiopia located in the northeastern part of the country $588 \mathrm{kms}$ far from the capital. The total geographical area of the region is about $270,000 \mathrm{~km}^{2}$. It is geographically located between $39 \mathbf{3}^{\circ}$ ' and $42^{\circ} 28^{\prime}$ East Longitude and $8^{\circ} 49^{\prime}$ and $14^{\circ} 30^{\prime}$ North Latitude. The climate in most of the region is hot with maximum temperature of $45^{\circ} \mathrm{C}$ in August and minimum temperature of $20{ }^{\circ} \mathrm{C}$ in January. The altitude ranges from $116 \mathrm{~m}$ below sea level to $1500 \mathrm{~m}$ above sea level. The region has an area of Low Land, with an irregular drainage system and depression, which, is $114 \mathrm{~m}$ below sea level as well as some of the exposed rocks. $35.47 \%$ of the region has an elevation less than $400 \mathrm{~m}$ above sea level whereas $51.44 \%$ has an elevation between 400 to 900 and $13.09 \%$ has an elevation above $900 \mathrm{~m}$ above sea level. The region has a number of perennial rivers that include Awash, Mille, Kesem Kebena, Awura, Gulina, Dewe, Borkena, Telalak, and numerous seasonal rivers that flows to different basins. In the region there are also a number of lakes, such as Lake Asahle, Lake Dalol, Lake Afdera, Lake Abe, and Lake Gemeri are some examples of the lakes in the region. The study was conducted in seven districts of afar national regional state namely Chifra, Erebti, Burimodayito, Gewane, Dalifage, Yallo and Elidar which are potential areas for camel.

\section{Study animals}

The study was conducted on traditionally managed camel herd selected from seven districts (Chifra, Gewane, Bure Mudaytu, Elidar, Yalo, Dalifage and Megale) of Afar region. For the prevalence study, age groups and sexes were randomly selected from the selected herds. Due to the absence of written records, the age of animal was determined by dentition. Study animal related information of each sampled camel such as sex, age and body condition score were collected at the time of the study. Camel breeds in Ethiopia are one humped which are categorized under camellus dromedarous breed. Animals that had not treated for internal parasites for at least two months during the study were considered for sampling.

\section{Study design}

A cross sectional study design was used to determine the occurrence and prevalence of GIT parasites in the selected districts. From each selected district two peasant associations (PAs) or kebeles were selected giving a total of 14 kebelles from the entire five zones of the region. The study districts and kebeles were selected based on the inclusion criteria such as potential camel population, accessibility, and willingness of the pastoralists to participate in the study.

\section{Sample size determination}

Sample size was determined according to Thrusfield (2005) using an average expected prevalence rate of $50 \%$ (as there was no previous report in the districts), $95 \%$ confidence intervals (Cl) and $5 \%$ desired accuracy. Accordingly a total of 384 animals were calculated to be included in the study. However, the sample size for GIT parasites was inflated to 407 in order to increase the representativeness of the samples to the wider population. Sampling animals were proportionally distributed to the selected districts and PAs based on their camel population.

\section{Laboratory analysis}

The fecal samples were collected per rectum with new, unused gloves for each animal. Collected samples were put into fecal pots, labeled and kept cool prior to transportation to the laboratory where they were immediately examined or stored at refrigerated temperature $\left(4^{\circ} \mathrm{C}\right)$ for a maximum of one day before processing. The sedimentation and floatation techniques as described by Hansen and Perry (1994) were used for parasite examination. Identification of eggs of each species of camel parasites were done according to the procedure described by Soulsby (1982) and Urquhart et al. (1987).

\section{Data analysis}

The collected data were entered and coded to computer using excel spreadsheets and analysis was carried out using STATA, version 11. The prevalence $(p)$ calculated as $p=d / n$, where $d$ is the number of camels diagnosed as having a given parasite egg/oocyst at that point in time and $n=$ number of camels at risk at that point in time. Descriptive statistics was used to show the frequencies and chi square analysis was used to identify factors associated with the occurrence of parasites. The level of significance was set at $P<0.05$.

\section{RESULTS}

Of 407 fecal samples examined, a total of 123 were found positive for at least one GIT parasite giving an overall prevalence of $30.22 \%$ (123/407). Positive camels were harbored and excreted helminthes and/or protozoan parasites. The prevalence of nematodes, protozoa, cestodes, and trematodes were $144(35.4 \%), 28(6.9 \%), 8(1.97 \%)$ and 5 (1.23\%), respectively (Table 1). Of the 132 positive facial samples, six types of helminthes/protozoan parasites 
eggs/oocyst encountered in descending order of prevalence were Strongylus sp. 68 (55.28\%), Trichuris 40 (32.52\%), Strongyloides sp. 36 (29.27\%), Coccidia 28 (22.76\%), Moniezia 8 (6.50\%), and Paraphystomum 5 (4.07\%). Majority of the GIT parasite infection type were occurred in single (17.44\%), while the remaining occurred in mixed infections with two (10.56\%), three (1.97\%) and four $(0.25 \%)$ parasites (Tables 2 and 3 ).

The occurrence of camel GIT helminthes in the present study was significantly influenced by age and body condition $(P<0.005)$, where significantly higher prevalence were observed in adult animals than young, and in animals with poor body condition than in animals with poor body condition (Table 4). Sex wise, the prevalence of GIT parasites in female and male camels were $96(23.59 \%)$ and 27 (6.63\%), respectively there was no significant variations. In addition, there were no significant differences in the prevalence of camel GIT infection among the selected study districts $(P>5 \%)$. Of the selected six districts higher camel GIT prevalence was observed in Gewane (5.65\%) followed by Yalo and Megale with 4.9\% prevalence rates in both districts (Table 4 ).

\section{Table 1 - Prevalence of camel GIT parasites in selected districts of Afar region}

\begin{tabular}{lccc} 
Parasite category & Parasite species & Positive number & Prevalence (\%) \\
\hline \multirow{2}{*}{ Nematodes } & Strongylus & 68 & 16.7 \\
& Trichuris & 40 & 9.83 \\
\hline Protozoan & Strongyloides & 36 & 8.85 \\
\hline Ceastode & Coccidia & 28 & 6.9 \\
\hline Trematodes & Moniezia & 8 & 1.9 \\
\hline
\end{tabular}

Table 2 - Species of camel GIT parasite infection identified and their prevalence in selected districts of Afar region

\begin{tabular}{|c|c|c|c|c|}
\hline \multirow[b]{2}{*}{ Infection type (N) } & \multirow[b]{2}{*}{ Family/ies } & \multirow[b]{2}{*}{ Species } & \multicolumn{2}{|c|}{ Prevalence } \\
\hline & & & $\begin{array}{l}\text { Frequency } \\
\text { (N) }\end{array}$ & $\begin{array}{c}\text { Percentage } \\
\text { (\%) }\end{array}$ \\
\hline \multirow{6}{*}{ Single (71) } & & Strongylus & 22 & 5.41 \\
\hline & Nematode & Strongyloides & 21 & 5.16 \\
\hline & & Trichuris & 4 & 0.98 \\
\hline & Protozoan & Coccidia & 16 & 3.93 \\
\hline & Cestode & Monezia & 6 & 1.47 \\
\hline & Trematode & Paramphistomum & 2 & 0.49 \\
\hline \multirow{6}{*}{ Two parasite (43) } & Nematode and Protozoan & Strongyloides \& Coccidia & 1 & 0.25 \\
\hline & Trematode and Nematode & Paramphistomum \& Strogylus & 2 & 0.49 \\
\hline & Nematode & Strongyiodes \& Strongylus & 2 & 0.49 \\
\hline & Nematode & Strongyloides \& Trichuris & 5 & 1.23 \\
\hline & Nematode and Protozoan & Strongylus \& Coccidia & 11 & 2.70 \\
\hline & Nematode & Strongylus \& Trichuris & 22 & 5.40 \\
\hline \multirow{3}{*}{ Three parasite $(8)$} & Cestode \& Nematode & Monezia, Strongylus \& Trichuris & 1 & 0.25 \\
\hline & Trematode and Nematode & Paramphistomum, Strongylus \& Trichuris & 1 & 0.25 \\
\hline & Nematode & Srongylus, Trichuris \& Strongyloides & 6 & 1.47 \\
\hline $\begin{array}{l}\text { Four parasite } \\
\text { (1) }\end{array}$ & Nematode \& Cestode & $\begin{array}{l}\text { Strongylus, Trichuris, Monezia \& } \\
\text { Strongyloid }\end{array}$ & 1 & 0.25 \\
\hline Total & & & 123 & 30.22 \\
\hline
\end{tabular}

Table 3 - Prevalence of camel GIT parasites observed in single and mixed infestation in selected districts of Afar region

\begin{tabular}{lcc} 
Infection type & Frequency (N) & Percentage (\%) \\
\hline Single & 71 & 17.44 \\
Two parasite & 43 & 10.57 \\
Three parasite & 8 & 1.97 \\
Four parasite & 1 & 0.24
\end{tabular}


Table 4 - Prevalence of Camel GIT parasites in relation to hypothesized risk factors

\begin{tabular}{|c|c|c|c|c|c|}
\hline Risk factors & & No. examined & No. positive & Prevalence (\%) & $X^{2}$ (p-value) \\
\hline \multirow{2}{*}{ Sex } & Female & 332 & 96 & 23.59 & \multirow{2}{*}{$5.41(0.228)$} \\
\hline & Male & 75 & 27 & 6.63 & \\
\hline \multirow{2}{*}{ Age } & Adult & 324 & 98 & 24.08 & \multirow{2}{*}{$8.62(0.0005)$} \\
\hline & Young & 83 & 25 & 6.14 & \\
\hline \multirow{2}{*}{$\begin{array}{l}\text { Body condition } \\
\text { score }\end{array}$} & Good & 280 & 17 & 4.18 & \multirow{2}{*}{$10.13(0.000)$} \\
\hline & Poor & 127 & 106 & 26.04 & \\
\hline \multirow{7}{*}{ Districts } & Chifra & 52 & 16 & 3.93 & \multirow{7}{*}{$7.92(0.84)$} \\
\hline & Gewane & 60 & 23 & 5.65 & \\
\hline & Bure Mudaytu & 51 & 14 & 3.44 & \\
\hline & Elidar & 55 & 14 & 3.44 & \\
\hline & Yalo & 60 & 20 & 4.91 & \\
\hline & Dalifage & 70 & 16 & 3.93 & \\
\hline & Megale & 59 & 20 & 4.91 & \\
\hline Total & & 407 & 123 & 30.22 & \\
\hline
\end{tabular}

\section{DISCUSSION}

Camel parasites are the most important camel health problems in Afar region of Ethiopia. The current finding indicated that the overall prevalence of camle GIT parasite was $30.22 \%$ in the selected study districts. The dominat parasites identified in the area were Strongylus sp. 68 (55.28\%), Trichuris 40 (32.52\%) Strongyloides sp. 36 (29.27\%), Coccidia 28 (22.76\%), Moniezia 8 (6.50\%), and Paraphystomum 5 (4.07\%) in descenmding order. Single parasitism (17.44\%) and mixed infection $\mathbf{1 0 . 4 6} \%$, was recorded in the camel rearing areas. The result was in line with the findings of Bekele, (2002). However, the present finding was lower than the studies of Mohammed et al. (2008) who reported 91.5\% prevalence rate of GIT parasites in camel.

This difference might be related to differences in the management practices and microclimates of the study areas. The study revealed adult camels $(24.08 \%)$ were more prone to infection than young camels. This finding was consistent with the study of Mohmuda et al. (2007), who reported an increasing rate of infection with age of camels. The variations could be exposure risk of adult camels due to physiological differences, such as stress, pregnancy, lambing, inadequate nutrition, and infectious diseases. In addition, a significantly higher GIT parasite prevalence was observed in camels with poor body condition than in camels in good body condition. This could be due to the impact of the parasites that causes weight loss, copious diarrhea and reduced feed intake.

The distribution of parasites among the different districts of the study was not significantly different which could be due to similarity on the management system of the animals across the region. The study also showed no significant differences between the two sexes. However, female camels (23.59\%) were more vulnerable to parasites than male camels $(6.63 \%)$. The probable reason could be stress factors that reduce immunity of female camels to infections (Magzoub et al., 2000). Similar results were also reported by other authors (Valcarcel and Romero, 1999). On contrarily, Gulland and Fox (1992), reported higher rate of infection in male than female camels.

\section{CONCULUSION AND RECOMMENDATIONS}

The study showed that gastro-intestinal parasites were prevalent in the study areas. The current finding indicated that the overall prevalence of camel gastro-intestinal tract parasite was $30.22 \%$ in the study districts. The dominant parasites identified in the area were Strongylus sp. 68(55.28\%), Trichuris 40 (32.52\%) Strongyloides sp. 36 (29.27\%), Coccidia 28 (22.76\%), Moniezia 8 (6.50\%), and Paraphystomum 5 (4.07\%) in descending order. single parasitism (17.44\%) and mixed infection $10.46 \%$, was recorded in the camel rearing areas. Therefore, it is important to undertake the detailed epidemiological investigations such as seasonal dynamics, fecal culture for larvae recovery and species identification to generate parasite mitigation methods.

\section{DECLARATIONS}

\section{Acknowledgements}

The authors acknowledge livestock owners, communities and officials in the study districts for their unreserved cooperation and assistance during field work. 
Authors' contribution

All authors contributed equally to this research work. All authors read and approved the final manuscript.

Availability of data and materials

Data will be made available up on request of the primary author.

Consent to publish

Not applicable.

\section{Competing interests}

The data can be available to the journal upon request.

Conflict of interest

The authors declare they have no competing of interests.

\section{REFERENCE}

Bekele T (2002). Epidemiological studies on GIT helminths of dromedary in semi-arid .lands of eastern Ethiopia. Veterinary Parasitology, 105: 139-152. DOI: https://doi.org/10.1016/s0304-4017(01)00583-0

Bikaner Website (2008). Online Article on Camel, National Research Center on Camel, Jorbeer, Bikaner (Rajasthan) India. https://nrccamel.icar.gov.in/

Borji H, Razmi G, Movassaghi AR, (2010): A study on gastrointestinal helminths of camels in Mashhad abattoir Iran. Iranian $\begin{array}{lllll}\text { journal of } & \text { Veterinary } & \text { Research, } & 11: & 174-179 .\end{array}$ https://citeseerx.ist.psu.edu/viewdoc/download?doi=10.1.1.1045.999\&rep=rep1\&type=pdf

Burger PA, Ciani E, and Faye B (2019). Old world camels in a modern world - a balancing act between conservation and genetic improvement. Animal Genetics, 50(6): 598-612. Doi: https://doi.org/10.1111/age.12858

Central Statistical Agency. (2009): Animal population census in Afar region. Addis Ababa, Ethiopia.

Desta AH (2019). Major helminth parasites of camelus dromedarius in afar pastoral area of Ethiopia. Iraqi Journal of Veterinary Sciences, 33: 117-122. DOI: https://doi.org/10.33899/ijvs.2019.125524.1046

Djerbouh A, Lafri I, Kechemir-Issad N and Bitam I (2018). Endo- and ectoparasites (Ixodidae) of camels (Camelus dromedarius) from Southern Algeria. Livestock Research for Rural Development, 30: Article \#141. http://www.Irrd.org//rrd30/8/djerb30141.html

Fentahun T (2020). Systematic review on gastrointestinal helminths of domestic ruminants in Ethiopia. Online Journal of Animal and Feed Research, 10(5): 216-230. Link

Gulland F and Fox M (1992): Epidemiology of Nematode Infections of Soay on St. Kilda. Parasitology, 105(3): $481-492$. https://doi.org/10.1017/S0031182000074667

Hansen and Perry J, and B. Perry (1994). Epidemiology, Diagnosis and Control of Helminthes Parasites of Ruminants $2^{\text {nd }}$ Ed. Nairobi, Kenya, Hrad, ISBN: 92-9055-703-1., Pp. 171. https://orcid.org/0000-0002-8599-7895 I Google Scholar

Hoter A, Rizk S, and Naim HY (2019). Cellular and molecular adaptation of arabian Camel to heat stress. Frontiers in Genetics, 10: 588. https://doi.org/10.3389/fgene.2019.00588

Magzoub M, Omer OH, HarouMagzoub EM, Omer M, Haroun OH, and Mahmoud OM (2000) Effect of season on gastrointestinal nematode infection in Saudi Arabian camels (Camelus dromedarius). Journal of Camel Practice Research, 7 (1): 107-108. Google Scholar

Mohamed AM, Mahmoud R, Abdella GA. and Abou EE. (2008). The influence of Some Nematode Parasitism on Lipid Metabolism and Lipoprotein Profile in Dromedary Camel. Journal of Camel Science, 1: 63-67. Llink: https://www.cabdirect.org/cabdirect/abstract/20103054788

Mohammed AK, Sackey AKB, and Gefu AO (2007). Common health problems of the one humped camel (Camelus dromedarius) introduced into sub-humid climate in Zaria, Nigeria. Research Journal of Animal Sciences, 1(1): 1-5. https://medwelljournals.com/abstract/?doi=rjnasci.2007.1.5

SOULSBY EJL (1982). Helminths. Arthropods and Protozoa of Domestic Animals, $7^{\text {th }}$ Ed. Bailliere Tindall, London, UK, PP.231-250. Link, Google Scholar

Thrusfield M (2005). Veterinary Epidemiology. 3rd edition, Blackwell Science Ltd., Oxford, London. UK. pp. 234-238. Google Scholar

Urge B, Mark T, and Siyoum T (2020). Identifying Helminthes Infection in Calves Reared by Smallholder Farmers in Central Areas of Ethiopia. International Journal of Scientific and Management Research, 3: 9-15. http://ijsmr.in/doc/ijsmr_01_6888_23.pdf

Urquhart GM, Armour J, and Duncan JL (1987). Veterinary Parasitology $3^{\text {rd }}$ End. Long man Scientific and Technical Burnt Mill, Harlow, UK. pp. 238. Google Scholar I https://www.abebooks.com/servlet/BookDetailsPL?bi=30660616938

Valcarcel F and Romero CG (1999). Prevalence and Seasonal Pattern of Trichostrongylus in a Dry Area Central Spain. Journal of Veterinary Medicine, Series B, 46(10): 673-681. https://doi.org/10.1046/j.1439-0450.1999.00297 Google Scholar 